\title{
sciendo
}

\section{Assessing Change of Direction Ability in a Spanish Elite Soccer Academy}

\author{
by \\ Asier Los Arcos' ${ }^{1}$, José F. Aramendiㄴ, Jose I. Emparanza ${ }^{3}$, Carlo Castagna , \\ Javier Yanci', Alejandro Lezáun ${ }^{5}$, Raúl Martínez-Santos ${ }^{1}$
}

\begin{abstract}
The aims of the study were: a) to analyze the reproducibility of the Modified Agility Test (MAT) according to two types of displacement (i.e. constrained [MATtop] vs. free [MATfree]), b) to examine the explanatory capacity of anthropometric characteristics and neuromuscular performance on the ability to change the direction (CODA), c) to look into the practical consequences of the types of displacement from the perspective of an elite soccer academy. 118 male soccer players (age: 16 (13-25) years old) from the same elite Spanish soccer academy (U13 to senior) were tested twice on two versions of the MAT (MATtop and MATfree), with 48 hours between testing sessions. Moreover, they were tested on linear-sprint performance, over $5 \mathrm{~m}$ (S5m) and $15 \mathrm{~m}$ (S15m), and the vertical jump (VJ) (countermovement jump with [ACMJ] and without an arm swing [CMJ]). The main findings were: a) the type of displacement did not affect the reliability of the CODA test; $b$ ) weight, S15m, ACMJ and CMJ variables explained close to $60 \%$ of CODA performance; c) MATtop (i.e. constrained displacement) and MATfree (i.e. free-displacement) CODA tests could show different profiles of development along the age groups; and d) the impact of the task's constraints was relatively higher in U16 and U17 groups. CODA seems to have a variable meaning depending on the characteristics of the test and the age of the participants.
\end{abstract}

Key words: agility, test, youth, soccer, athletics.

\section{Introduction}

Several authors have suggested that the change of direction ability (CODA) is an essential quality for soccer players, who, in an endurance context, are required to turn, sprint and change pace during matches (Stølen et al., 2005). Specifically, Reilly (1990) reported about 1000 changes of pace and direction during a game and Bloomfied et al. (2007a, 2007b) recorded an average of 9.3 decelerations every 15 minutes and more than 700 changes of direction per game in professional matches. CODA tests are habitually included in the batteries that try to describe and assess the physical fitness of soccer players
(Brughelli et al., 2008; Fiorilli et al., 2017; Pojskic et al., 2018) or seek to distinguish between elite and sub-elite young soccer players (Gil et al., 2007; Hachana et al., 2014; Reilly et al., 2000; Trecroci et al., 2018a, 2018b).

Operationally, CODA is understood as the performance (i.e. time scored) over pre-planned sprint courses (Brughelli et al., 2008; Young and Willey, 2010). Among the numerous tests used to assess CODA, the T-Test (Chaouachi et al., 2012; Little and Williams, 2005; Sporis et al., 2010) designed by Seminick (1990) and its later modified versions (MAT) (Sassi et al., 2009; Silva

\footnotetext{
1 - Department of Physical Education and Sport, University of the Basque Country, UPV/EHU, Vitoria-Gasteiz, Spain.

2 - Osasunkirol, Salud y Deporte, Hondarribia, Spain.

3 - Clinical Epidemiology Unit, Hospital Universitario Donostia. Donostia-San Sebastián, Spain.

4 - Football Training and Biomechanics Laboratory, Italian Football Federation (FIGC), Technical Department, Coverciano (Florence), Italy.

5 - Club Atlético Osasuna, Pamplona, Spain.
} 
et al., 2011) have been proposed as valid and reliable, having been widely used in order to assess CODA in soccer. Being originally designed for basketball players, the T-Test and its modifications require 4 changes of direction and the combination of frontal (forward and backward) and lateral (without crossing feet) displacements. The modified versions of the TTest (MAT) shortened the pre-planned sprint course from $36.576 \mathrm{~m}$ to $20 \mathrm{~m}$, trying to adapt the original protocol to the reported CODA activity during soccer and other games (Sassi et al., 2009). However, similarly to the T-Test, the MAT still involves elements that are not soccer specific (i.e. hand-touching of course lines and sideward and backward sprinting) for outfield players (Bloomfield et al., 2007c; Little and Williams, 2005; Strøyer et al., 2004). Several years ago two new versions of the MAT have been proposed with the aim of adapting it to the specificity of soccer: MATtop (Yanci et al., 2013) allows the players to touch the highest part of the cone, while MATfree (Yanci et al., 2014) imposes no constraints in terms of displacement or cone-touching. MATfree could be considered the most specific one because the players are not required to touch the ground with the hand nor to apply backward and lateral (without crossing feet) displacements as in other sports (i.e., basketball and racquet sports) (Bloomfield et al., 2007c; Little and Williams, 2005; Strøyer et al., 2004).

Because of its complex nature, multiple factors (i.e., technique, straight sprinting speed, leg muscle qualities, anthropometry and so on) can condition this ability (Sheppard and Young, 2006). Consequently, the characteristics of the tests (i.e., time to complete the test, the number of CODs, primary application of force throughout the entire test) determine the importance attributed to those factors (Brughelli et al., 2008; Chaouachi et al., 2012) and the definition of the CODA itself. Therefore, the aim of this study was to look into the practical consequences that certain changes in the measurement test (i.e. free displacement) can have on performance from the perspective of an elite soccer academy. Our research questions were whether the CODA tasks' constraints affected their applicability and their ability to discriminate between groups and players in a professional soccer academy in Spain. Hypothetically, we assumed that players' performance would not be affected by the lack of constraints in the definition of the task.

\section{Methods}

\section{Participants}

One hundred and eighteen male soccer players volunteered to participate in the study. They all were players from the same soccer academy belonging to a club that took part in the Spanish First Division League. These young soccer players belonged to 7 different age categories: senior-professional (the second team of the club that competed in the Spanish Second division B), junior (Under-19 and Under-17), cadets (Under-16 and Under-15) and child category (Under-14 and Under-13). The players' physical and anthropometric characteristics are presented in Table 1. Before the beginning of the study, written informed consent was obtained from the players and/or their legal guardians. The study was conducted according to the Declaration of Helsinki and in agreement with the guidelines of the Institutional Review Committee of the Sports and Youth Institute of Navarre.

\section{Procedures}

Two CODA tests (i.e., MATtop and MATfree) were included in the battery habitually used in the soccer academy to assess physical fitness of players. The collection of data was made in the last period of physical evaluation of the season (i.e., May) over three sessions with the following distribution of tests: a) Session 1: three performances of MATtop and MATfree randomly distributed, b) Session 2: three additional performances of MATtop and in MATfree randomly distributed, and c) Session 3: linearsprint performance over $5 \mathrm{~m}$ ( $\left.\mathrm{S}_{5 \mathrm{~m}}\right)$ and $15 \mathrm{~m}\left(\mathrm{~S}_{15 \mathrm{~m}}\right)$ and two vertical jump (VJ) tests (countermovement jump with (ACMJ) and without an arm swing (CMJ)). Anthropometric measures were made before the first session. All the players were familiarized with the MAT tests in a previous session and had a rest interval of 48 hours between testing sessions. The players were fully acquainted with the rest of the tests.

Testing took place indoors on a synthetic court. Before each session a standardized warmup, consisting of 3 min self-paced low-intensity running, skipping and scalping exercise, strides, and two acceleration drills, was performed. Strong verbal encouragement was provided to the 
players during all the tests to elicit maximal efforts.

In this study, the quality of the data of both tests (I.e., MATtop and MATfree) was assessed using relative and absolute reliability methods (Atkinson and Nevill, 1998; Bland and Altman, 1995; Hopkins et al., 2009; Sassi et al., 2009) considering a short term re-test design (48 h apart). In order to check the construct of the CODA we considered the differences in performance between age groups and the association between the performance in the CODA tests and the rest of the independent variables (Sheppard et al., 2006): sprint performance ( $\mathrm{S}_{5 \mathrm{~m}}$ and $\left.\mathrm{S}_{15 \mathrm{~m}}\right), \mathrm{VJ}$ performance (CMJ and $\mathrm{ACMJ}$ ) and anthropometrical values. In order to evaluate the global practical information provided by each test we calculated the intragroup correlation between both tests by means of the Kendall rank association coefficient.

Change of direction ability (CODA)

MATtop: Modified Agility Test touching the top of the cone. In fulfilment of the protocol of the Modified agility test (MAT) outlined by Pauole et al. (2000) and Sassi at al. (2009) the participant began with both feet behind the starting line A. At their own discretion, participants sprinted forward to cone B and touched it with their right hand. Facing forward and without crossing feet, they shuffled to the left to cone $C$ and touched it with their left hand. The players then shuffled to the right to cone D and touched it with their right hand, shuffling back immediately after to the left to cone B to touch it. Finally, participants ran backward as quickly as possible returning to line A (Sassi et al., 2009). The only difference was that the players were allowed to touch the top of the cone $(30 \mathrm{~cm})$ instead of its base (Yanci et al., 2013).

MATfree: Modified Agility Test without indications about how to displace or which part of the cones to be touched. The only change with respect to the protocol of the MATtop was that in MATfree players were not required to move sideways and backwards at any time (Yanci et al., 2014). Table 2 shows the characteristics and the comparison of the MAT, MATtop and MATfree procedures.

Each player randomly completed three maximal performances of each of the CODA tests (i.e., MATtop and MATfree) interspersed with 3 min of passive recovery. The player's CODA performance was considered to be the shortest time needed to cover the set protocol distance in both tests. Any attempt that did not meet the considered requirements was excluded and repeated. Scores were recorded with photocellbeams set on tripods approximately $0.40 \mathrm{~m}$ above the floor level (Yanci et al., 2014) and positioned 2 $\mathrm{m}$ apart on either side of the starting line (DSD Laser System, Barcelona, Spain).

\section{Sprinting ( $S_{5 m}$ and $S_{15 m}$ )}

Each player performed an acceleration test consisting of three maximal sprints over $15 \mathrm{~m}$, with 2 min of passive recovery between each sprint (Los Arcos et al., 2014). Players were placed $0.30 \mathrm{~m}$ away from the starting line and began the test when they felt ready (Los Arcos et al., 2014). Sprint times were collected with accuracy of \pm 0.001 s using photocell beams (DSD Laser System, Barcelona, Spain) set at 0, 5 and $15 \mathrm{~m}$ from the starting line, placed $0.4 \mathrm{~m}$ above the ground. The timer was activated automatically as the participant passed through the first gate at the $0.0 \mathrm{~m}$ mark recording split times for 5, 10 and 15 m sprints.

\section{Vertical jump performance (CMJ and ACMJ)}

Soccer players' vertical jumps (VS), countermovement jumps (CMJ) and arm swing countermovement jumps (ACMJ) were tested using infrared bars (Opto Jump Next, Microgate, Bolzano, Italy) according to the procedures proposed by Bosco et al. (1983). Players performed three CMJs and three ACMJs with at least a 3 min rest interval. Resting time between attempts was $20 \mathrm{~s}$. In CMJs the hands were placed on the hips during take-off, flight, and landing phases and the maximal flexion of the knees during the take-off phase was required to be approximately $\sim 90^{\circ}$ (Bosco and Komi, 1979). In addition, a minimal flexion of the trunk during the take-off was permitted (Bosco and Komi, 1979). In comparison to CMJs, players were not obliged to place the hands on the hips during take-off, flight, and landing phases. Any jump that did not meet the considered requirements was repeated.

\section{Anthropometric profile}

All anthropometric measures were made in the afternoon by the same expert technician. Firstly, body mass and stature of each player were measured (Seca 799 and Seca 220, Hamburg, 
Germany). Next, skinfold measurements were carried out at four sites using a skinfold caliper (Holtain Ltd., Crymych, UK): triceps, subscapular, abdominal and suprailiac. Each measurement was made 3 times according to the recommendations of the Spanish International Group of Kinanthropometry and International Standards for Anthropometric Assessment (ISAK) and the average value was considered for each skinfold. Finally, the body fat percentage was estimated using the equation proposed by Faulkner (1968): body fat $(\%)=\sum$ skinfolds (tríceps + subscapular + suprailiac + abdominal $) \cdot 0.153+5.783$.

\section{Statistical Analysis}

The results are presented as mean \pm standard deviation (SD). The normality of the data was confirmed using the Shapiro-Wilk test. We used custom-made spreadsheets to analyse the magnitude of the differences in CODA performance from the test to retest (Hopkins, 2006) and between categories. Practical significance of the differences was assessed by calculating the Cohen's d effect size (Cohen, 1988). Effect sizes (ES) between $<0.2,0.2-0.6,0.6-$ $1.2,1.2-2.0$, and 2.0-4.0 were considered as trivial, small, moderate, large and very large, respectively (Hopkins et al., 2009). Probabilities were also calculated to establish whether the true (unknown) differences were lower, similar or higher than the smallest worthwhile difference or change ( 0.2 multiplied by the between-subject $S D$, based on the Cohen's effect size principle). Quantitative chances of higher or lower differences were evaluated qualitatively as follows: $<1 \%$, almost certainly not; $1-5 \%$, very unlikely; 5-25\%, unlikely; 25-75\%, possible; 75-95\%, likely; 95-99\%, very likely; > 99\%, almost certain. If the chances of having higher or lower values than the smallest worthwhile difference were both $>5 \%$, the true difference was assessed as unclear. Reliability calculations were made for MATtop and MATfree considering the value of the best attempt. The relative reliability was assessed using the Intraclass Correlation Coefficient (ICC) (Hopkins et al., 2009) and the magnitude of the effect for the ICC analysis $(90 \%$ confidence limits) was provided according to the arbitrary categorization scale suggested by Coppieters et al. (2002). The absolute reliability was assessed calculating the Typical Error of the Measurement (TEM) (Hopkins et al., 2009). The coefficient of variation (CV) was calculated for all variables to determine the stability of the values between trials $(\mathrm{CV}=[\mathrm{SD} / \mathrm{mean}] \times 100)$ (Atkinson and Nevill, 1998). The construct validity was assessed using an ANOVA design (inter-groups design) with the Bonferroni post-hoc test. Association between the considered to be independent variables and CODA test performances was evaluated using a backwards steps wise multiple regression approach. Kendall's tau correlation coefficients were calculated for each group in order to assess the intragroup performance level of each player according to each test. The analyses were performed using the SYSTAT 13 statistical software. Significance was set a priori at $5 \%$.

\section{Results}

Test-retest differences were trivial for MATtop $(5.63 \pm .35$ vs $5.60 \pm .35$, ES $=-0.13 \pm 0.08$, likely) and MATfree (5.16 \pm 0.31 vs $5.12 \pm 0.29$, ES $=-0.17 \pm 0.07$, likely). ICC, TEM and CV values were $0.97,0.19$ and 10.1 for MATtop and 0.92, 0.30 and 10.7 for MATfree.

Table 3 shows the overall and age specific results for all the tests of physical fitness.

The performance level in MATtop correlated with body mass $(r=0.690, p<0.001)$, body height $(\mathrm{r}=0.639, P<0.001), \mathrm{S}_{5 \mathrm{~m}}(\mathrm{r}=0.602, P<0.001), \mathrm{S}_{15 \mathrm{~m}}$ $(\mathrm{r}=0.673, p<0.001), \mathrm{CMJ}(\mathrm{r}=0.703, p<0001)$ and ACMJ $(r=0.696, p<0.001)$. Multiple regressions for MATtop showed the best fit $(60 \%$ of explained variance) when including body mass, $\mathrm{S}_{15 \mathrm{~m}}$ and $\mathrm{CMJ}$ variables. The performance level in MATfree was statistically significant with body mass $(\mathrm{r}=$ $0.685, p<0.001)$, body height $(\mathrm{r}=0.660, p<0.001)$, $\mathrm{S}_{5 \mathrm{~m}}(\mathrm{r}=0.609, p<0.001), \mathrm{S}_{15 \mathrm{~m}}(\mathrm{r}=0.720, p<0.001)$, $\mathrm{CMJ}(\mathrm{r}=0.698, p<0.001)$ and ACMJ $(\mathrm{r}=0.721, p<$ 0.001). Multiple regressions for MATfree showed the best fit (62\% of explained variance) when including body mass, $\mathrm{S}_{15 \mathrm{~m}}$ and ACMJ variables.

Significant $(p<0.05)$ and most likely large/very-large differences (ES $=1.74-2.45$ ) were found between MATtop and the MATfree scores (MATfree < MATtop) in all categories. The mean improvement ranged from a maximum of $9.82 \%$ (U-14) to a minimum of $7.32 \%$ (U-16).

Tables 4 and 5 show the pairwise ANOVA comparisons between age groups for MATfree and MATtop, respectively, showing significant differences between U13 (MATfree: ES $=1.16-$ 3.23; MATtop: $\mathrm{ES}=1.03-3.59)$ and the rest of the 
groups and between U14 players (MATfree: ES = 1.28-1.92; MATtop: ES = 1.86-2.33) and the rest of categories except for U15 players. The U15 group happened to be slower than any older group in MATtop, but not in all cases in MATfree.

The Kendall ranked correlation test between MATfree and MATtop showed the following intragroup tau values: Senior (tau $=0.65, p<$ $0.000), \mathrm{U}-19(\mathrm{tau}=0.53, p<0.003), \mathrm{U}-17(\operatorname{tau}=0.28$, $p<0.200), \mathrm{U}-16$ (tau $=0.41, p<0.036), \mathrm{U}-15(\mathrm{tau}=$ $0.50, p<0.008)$, U-14 (tau $=0.48, p<0.002$ ) and U$13(\operatorname{tau}=0.53, p<0.002)$.

Table 1

Participants' characteristics according to their playing category.

The data are mean \pm standard deviation.

\begin{tabular}{|c|c|c|c|c|c|c|c|c|}
\hline & $\begin{array}{l}\text { Senior } \\
(n=19)\end{array}$ & $\begin{array}{c}\text { U-19 } \\
(n=12)\end{array}$ & $\begin{array}{c}\mathrm{U}-17 \\
(\mathrm{n}=15)\end{array}$ & $\begin{array}{c}\text { U-16 } \\
(n=15)\end{array}$ & $\begin{array}{c}\text { U-15 } \\
(n=17)\end{array}$ & $\begin{array}{c}\mathrm{U}-14 \\
(\mathrm{n}=22)\end{array}$ & $\begin{array}{c}U-13 \\
(n=18)\end{array}$ & $\begin{array}{c}\text { Total } \\
(n=118)\end{array}$ \\
\hline Age (years) & $22.1 \pm 2.0$ & $18.3 \pm 0.7$ & $17.1 \pm 0.3$ & $16.3 \pm 0.3$ & $15.2 \pm 0.2$ & $14.2 \pm 0.2$ & $13.2 \pm 0.2$ & $16.5 \pm 3.0$ \\
\hline Body mass $(\mathrm{kg})$ & $72.8 \pm 6.0$ & $74.1 \pm 6.1$ & $72.1 \pm 4.9$ & $67.1 \pm 5.8$ & $64.9 \pm 9.5$ & $55.4 \pm 6.4$ & $50.1 \pm 6.3$ & $64.4 \pm 10.9$ \\
\hline $\begin{array}{l}\text { Body height } \\
\qquad(\mathrm{cm})\end{array}$ & $179.3 \pm 6.7$ & $182.2 \pm 5.3$ & $180.0 \pm 5.2$ & $178.2 \pm 4.5$ & $174.7 \pm 7.6$ & $169.0 \pm 5.6$ & $161.6 \pm 8.3$ & $174.4 \pm 9.3$ \\
\hline Body fat (\%) & $11.1 \pm 1.1$ & $10.4 \pm 0.8$ & $11.1 \pm 1.0$ & $10.3 \pm 0.6$ & $11.2 \pm 1.4$ & $10.4 \pm 0.9$ & $11.1 \pm 1.7$ & $10.8 \pm 1.2$ \\
\hline
\end{tabular}

Table 2

Different T-design test characteristics (previous and present study).

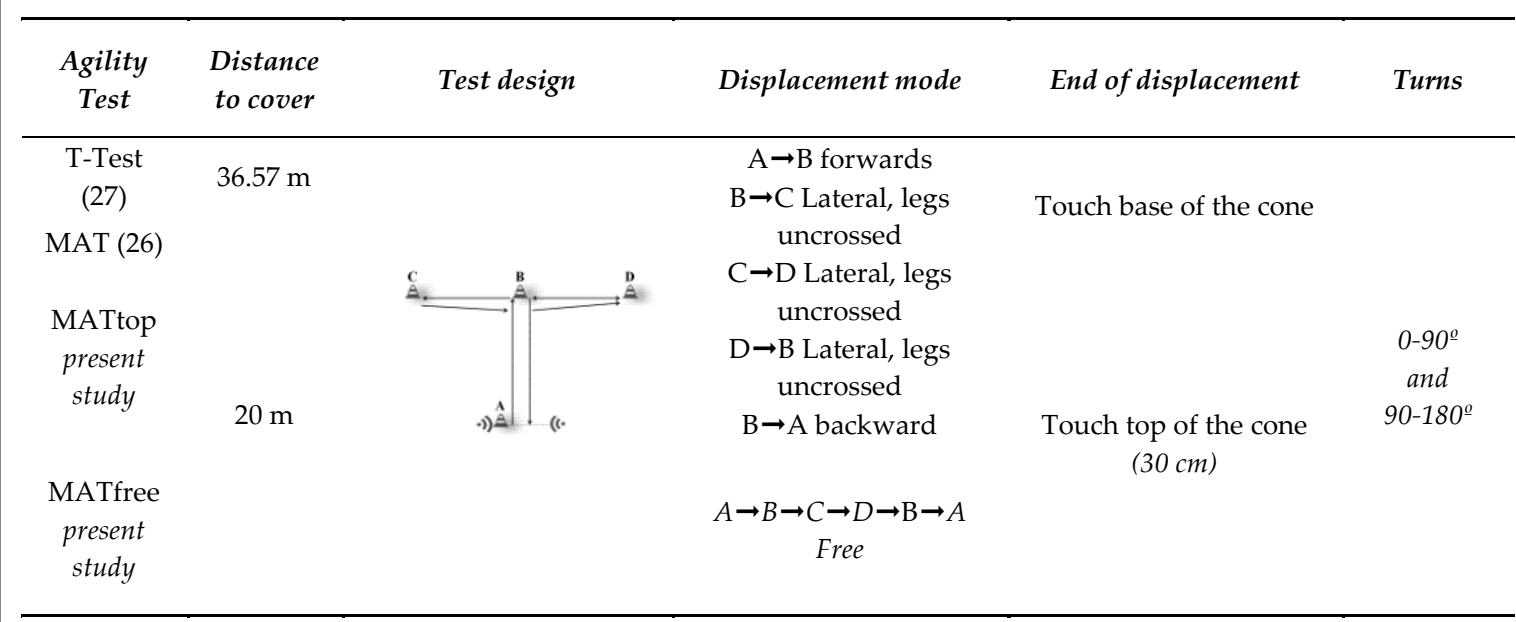

MAT $=$ Modified Agility Test; MATfree $=$ Modified Agility Test Free. 
Table 3

Physical performance results according to the playing category.

The data are mean \pm standard deviation.

\begin{tabular}{|c|c|c|c|c|c|c|c|c|}
\hline & $\begin{array}{l}\text { Senior } \\
(n=19)\end{array}$ & $\begin{array}{c}\text { U-19 } \\
(n=12)\end{array}$ & $\begin{array}{c}\text { U-17 } \\
(n=15)\end{array}$ & $\begin{array}{c}\text { U-16 } \\
(n=15)\end{array}$ & $\begin{array}{c}\text { U-15 } \\
(\mathrm{n}=17)\end{array}$ & $\begin{array}{c}\mathrm{U}-14 \\
(\mathrm{n}=22)\end{array}$ & $\begin{array}{c}\text { U-13 } \\
(n=18)\end{array}$ & $\begin{array}{c}\text { Total } \\
(n=118)\end{array}$ \\
\hline MATtop (s) & $5.39 \pm 0.23$ & $5.28 \pm 0.17$ & $5.33 \pm 0.18$ & $5.35 \pm 0.19$ & $5.66 \pm 0.22$ & $5.84 \pm 0.23$ & $6.07 \pm 0.21$ & $5.60 \pm 0.35$ \\
\hline MATfree (s) & $4.98 \pm 0.18$ & $4.83 \pm 0.12$ & $4.92 \pm 0.14$ & $4.96 \pm 0.21$ & $5.15 \pm 0.17$ & $5.27 \pm 0.22$ & $5.52 \pm 0.20$ & $5.12 \pm 0.29$ \\
\hline $\mathrm{S}_{5 \mathrm{~m}}(\mathrm{~s})$ & $0.96 \pm 0.03$ & $0.96 \pm 0.04$ & $1.00 \pm 0.05$ & $1.00 \pm 0.04$ & $1.05 \pm 0.07$ & $1.08 \pm 0.06$ & $1.08 \pm 0.06$ & $1.02 \pm 0.07$ \\
\hline $\mathrm{S}_{15 \mathrm{~m}}(\mathbf{s})$ & $2.30 \pm 0.07$ & $2.32 \pm 0.07$ & $2.34 \pm 0.07$ & $2.37 \pm 0.07$ & $2.48 \pm 0.14$ & $2.55 \pm 0.13$ & $2.58 \pm 0.13$ & $2.43 \pm 0.15$ \\
\hline CMJ $(\mathrm{cm})$ & $42.4 \pm 5.5$ & $45.4 \pm 4.3$ & $45.9 \pm 5.3$ & $46.2 \pm 5.1$ & $39.3 \pm 4.8$ & $36.7 \pm 4.4$ & $32.6 \pm 3.9$ & $40.5 \pm 6.7$ \\
\hline ACMJ (cm) & $50.0 \pm 6.0$ & $51.9 \pm 4.9$ & $51.3 \pm 5.6$ & $52.7 \pm 5.1$ & $45.9 \pm 4.4$ & $43.2 \pm 5.7$ & $37.9 \pm 4.8$ & $46.8 \pm 7.2$ \\
\hline
\end{tabular}

MAT = Modified Agility Test; MATFREE = Modified Agility Test Free; $S_{5 m}=$ acceleration in a $5 \mathrm{~m}$ test; $S_{15 m}=$ acceleration in a $15 \mathrm{~m}$ test; $C M J=$ height of a counter movement jump; $A C M J=$ height of an arm swing counter movement jump.

Table 4

ANOVA pair wise comparison with the Bonferroni adjustment between

the MATfree and the players' category.

\begin{tabular}{cccccccc}
\hline & Senior & U-19 & U-17 & U-16 & U-15 & U-14 & U-13 \\
\hline Senior & & & & & & & \\
U-19 & NS & & & & & & \\
U-17 & NS & NS & & & & & \\
U-16 & NS & NS & NS & & & & \\
U-15 & NS & $*$ & $*$ & NS & & & \\
U-14 & $*$ & $*$ & $*$ & $*$ & NS & & \\
U-13 & $*$ & $*$ & $*$ & $*$ & $*$ & $*$ & \\
\hline
\end{tabular}

* = significant difference, $p<.05 ; \mathrm{NS}=$ no significant differences; $M A T F=$ Modified Agility Test Free.

Effect Size (ES) and probabilities

U-13 vs U-14/U-15/U-16/U-17/U-19/Senior: ES =-1.16 - -3.23, most-likely moderate/very large

U-14 vs U-16/U-17/U-19/Senior: $E S=-1.28-1.92$, most-likely large

U-15 vs U-17/U-19: ES =-1.26 - -1.72, most-likely large 
Table 5

ANOVA pair wise comparison with the Bonferroni adjustment between MATtop and the players' category.

\begin{tabular}{cccccccc}
\hline & Senior & U-19 & U-17 & U-16 & U-15 & U-14 & U-13 \\
\hline Senior & & & & & & & \\
U-19 & NS & & & & & \\
U-17 & NS & NS & & & & \\
U-16 & NS & NS & NS & & & \\
U-15 & $*$ & $*$ & $*$ & $*$ & & \\
U-14 & $*$ & $*$ & $*$ & $*$ & NS & \\
U-13 & $*$ & $*$ & $*$ & $*$ & $*$ & $*$ \\
\hline
\end{tabular}

* = significant difference, $p<.05 ;$ NS = no significant differences; MATF = Modified Agility Test Free.

Effect Size (ES) and probabilities

U-13 vs U-14/U-15/U-16/U-17/U-19/Senior: ES = -1.03 - -3.59, very/most-likely moderate/very-large

U-14 vs U-16/U-17/U-19/Senior: ES = -1.86 - -2.33, most-likely large/very-large

U-15 vs U-16/U-17/U-19/Senior: ES = -1.26 - -1.72, most-likely large

\section{Discussion}

The aim of the study was to assess the applicability of two specific T-design CODA tests (i.e., MATtop and MATfree) in an elite soccer academy. The main findings were: a) both tests were reliable in order to produce scientifically and practically valid data when assessing the CODA in young soccer players; b) body mass, S15m and ACMJ variables explained $62 \%$ of the common variance for MATfree, while body mass, S15m but CMJ variables explained $60 \%$ for MATtop; c) MATfree and MATtop could show different profiles of development along the age groups, and d) the impact of the task's constraints was relatively higher in U16 and U17 groups.

Similarly to the MAT (i.e., touching the base of the cone with lateral and backwards displacements) (Sassi et al., 2009) and to the MATtop (i.e., touching the top of the cone and lateral and backwards displacements), we found trivial test-retest differences $(\mathrm{ES}=0.13-0.21)$ and high reliability scores for the MATfree. Therefore, the requirement of touching the top of the cone and the involvement of free movement did not affect the quality of the data.

Chaouachi et al. (2012) were the first to analyse the alleged components of a T-design test in senior soccer players using the universal-model components for the CODA (Sheppard and Young, 2006). Using the T-Test as a dependent variable, their Stepwise multiple regression showed R2 of 0.45 obtaining significant effects $(\mathrm{p}<0.05)$ for $5 \mathrm{~m}$ SS, height, QuadConc (quadriceps concentric isokinetic strength at $60^{\circ} \cdot \mathrm{s}-1$ ) and QuandEIm\% (percentage difference of right vs left eccentric isokinetic strength, $60^{\circ} \cdot \mathrm{s}-1$, of quadriceps). In our study, body mass, S15m and ACMJ variables explained $62 \%$ of the common variance for MATfree, and body mass, S15m and CMJ variables explained $60 \%$ of the common variance for MATtop. Bearing in mind the age span of the 
groups of our study, and despite the important variations in body dimensions, no significant effect of body height was detected, in contrast to Chaouachi et al. (2012): body mass had significant effects $(p<0.05)$ for MATtop and MATfree, but not for the T-Test in Tunisian National Soccer League 1. Interestingly, while the CMJ and a quintuple horizontal jump test did not contribute to the T-Test performance for senior soccer players (Chaouachi et al., 2012), and no significant regreession equation could be found for NCAA woman Division I and II soccer players on the MATtop after considering, among others, vertical jumping as a factor (Lockie et al., 2018), the explanatory jumping factor varied from MATfree to MATtop in this study. That is, the primacy of a more open drill (i.e., ACMJ) for the freedisplacement test and a closer drill (i.e., CMJ) for the constrained-displacement test can indicate the existence of slightly different CODA profiles, as far as lower limbs are concerned. These results suggest that, in addition to the characteristics of the players, the distance and the displacement mode of the T-design test (T-Test vs. MAT) determine the contribution of each factor to the performance.

Our results are congruent with previous studies that tested soccer players with MATfree. Yanci et al. (2014) conducted a study with 39 third division Spanish soccer players reporting a mean score of $4.89 \pm .29 \mathrm{~s}$, and Yanci et al. (2016) carried out an experimental study with a Spanish semiprofessional team (2nd division B) reporting 4.92 \pm .22 and $4.87 \pm .25$ scores in the pretest for both groups. These values, showing a slightly higher variance, are very similar to the results obtained by the groups older than U-16 in our research. In this sense, there are no differences between the four oldest groups (i.e. Senior, U-19, U-17 and U16) in MATfree nor in MATtop, after the peak height velocity (Deprez et al., 2015; MendezVillanueva et al., 2011). Similarly, Loturco et al. (2019) did not find differences in change of direction speed between U17 (16.3 \pm 0.2 years) and U20 (19.1 \pm 0.4 years) players from top-level Brazilian soccer clubs. Moreover, senior soccer players showed a likely to very likely lower COD speed performance than U17 and U20 players (Loturco et al., 2019). In addition, Mujika et al. (2009) did not find differences between Spanish first division and junior players belonging to the same club in the $15 \mathrm{~m}$ CODA test. Among other factors (e.g. the characteristics of the tests), the absence of differences could be due to the reduction of individual variations in motor coordination that occurs in the mid-teenage years (Spencer et al., 2011), the effects of a prolonged exposure to "concurrent" training (i.e., highvolume of technical and tactical training in detriment to neuromuscular training) (Loturco et al., 2018), or the ineffectiveness of the neuromuscular training programs used in different stages of player's maturation (Loturco et al., 2019).

The effect of the aforementioned peak height velocity and its alleged impact on the CODA could appear at the bottom part of Tables 5 and 6 in relation to the absence or presence of differences between the U-15 group and the immediately preceding (U-14) or following (U-16) ones. In MATfree, apart from the surprising absence of differences between U-15s and seniors, there was no difference between consecutive groups from U-14 onwards; however, in MATtop there were large differences between U-15s and U-16s. U-15 appears to be the turning point of this CODA and further research is required to confirm or discard the existence of two separate logics of CODA development in relation to the definition of the CODA itself. Moreover, the intragroup Kendall ranked correlation tests between MATfree and MATtop show that the comparative performance level of a player can vary dramatically depending on the definition of the task with values of tau ranging from 0.28 (U-17 group) to 0.65 (Senior group).

Displacement constraints cannot be discarded as a relevant factor when assessing the CODA in elite young soccer players. Further research could consider the maturation level of the younger participants, the comparison with other team sports (i.e. basketball and handball) in which lateral and backwards displacement can be more specific than in soccer, and the collection of more data from different groups for a better management of the errors of measurement. The practical interest of testing the CODA in an elite soccer academy could be elucidated getting to know whether the differences found in this research in the younger groups were due to mere neuromuscular factors rather than coordination and agility issues. 


\section{References}

Atkinson G, Nevill AM. Statistical methods for assessing measurement error (reliability) in variables relevant to sports medicine. Sport Med, 1998; 26(4): 217-238

Bland JM, Altman DG. Comparing two methods of clinical measurement: a personal history. Int J Epidemiol, 1995; 24 Suppl 1: S7-14

Bloomfied J, Polman R, O'Donoghue P. Deceleration movements performed during FA Premier League soccer matches. J Sports Sci Med, 2007a; Suppl 10: 6

Bloomfied J, Polman R, O’Donoghue P. Turning movements performed during FA Premier League soccer matches. J Sports Sci Med, 2007b; Suppl 10: 9

Bloomfield J, Polman R, O'Donoghue P. Physical Demands of Different Positions in FA Premier League Soccer. J Sports Sci Med, 2007; 6(1): 63-70

Bosco C, Komi PV. Mechanical characteristics and fiber composition of human leg extensor muscles. Eur J Appl Physiol Occup Physiol, 1979; 41(4): 275-284

Bosco C, Luhtanen P, Komi PV. A simple method for measurement of mechanical power in jumping. Eur J Appl Physiol Occup Physiol, 1983; 50(2): 273-282

Brughelli M, Cronin J, Levin G, Chaouachi A. Understanding change of direction ability in sport: a review of resistance training studies. Sports Med, 2008; 38(12): 1045-1063

Chaouachi A, Manzi V, Chaalali A, Wong DP, Chamari K, Castagna C. Determinants analysis of change-ofdirection ability in elite soccer players. J Strength Cond Res, 2012; 26(10): 2667-2676. https://doi.org/10.1519/JSC.0b013e318242f97a

Cohen J. Statistical power analysis for the behavioral sciences. (Second Edition). L. Erlbaum Associates; 1988

Coppieters M, Stappaerts K, Janssens K, Jull G. Reliability of detecting «onset of pain» and «submaximal pain» during neural provocation testing of the upper quadrant. Physiother Res Int, 2002; 7(3): 146-156

Deprez D, Fransen J, Boone J, Lenoir M, Philippaerts R, Vaeyens R. Characteristics of high-level youth soccer players: variation by playing position. J Sport Sci, 2015; 33(3): 243-254. https://doi.org/10.1080/02640414.2014.934707

Faulkner JA. Physiology of swimming and diving. In: H.Falls. Exercise physiology, Baltimore: Academic Press; 1968

Fiorilli G, Iuliano E, Mitrotasios M, Pistone EM, Aquino G, Calcagno G, di Cagno A. Are Change of Direction Speed and Reactive Agility Useful for Determining the Optimal Field Position for Young Soccer Players? J Sports Sci Med, 2017; 16(2): 247-253

Gil S, Ruiz F, Irazusta A, Gil J, Irazusta J. Selection of young soccer players in terms of anthropometric and physiological factors. J Sports Med Phys Fit, 2007; 47(1): 25-32

Hachana Y, Chaabène H, Ben Rajeb G, Khlifa R, Aouadi R, Chamari K, Gabbett TJ. Validity and reliability of new agility test among elite and subelite under 14-soccer players. PloS One, 2014; 9(4): e95773. https://doi.org/10.1371/journal.pone.0095773

Hopkins WG. Spreadsheets for analysis of controlled trials with adjustment for a predictor. Sportscience, 2006; 10: 46-50

Hopkins WG, Marshall SW, Batterham AM, Hanin J. Progressive statistics for studies in sports medicine and exercise science. Med Sci Sport Exercise, 2009; 41(1): 3-13. https://doi.org/10.1249/MSS.0b013e31818cb278

Little T, Williams AG. Specificity of acceleration, maximum speed, and agility in professional soccer players. J Strength Cond Res, 2005; 19(1): 76-78. https://doi.org/10.1519/14253.1

Lockie RG, Dawes JJ, Jones MT. Relationships between Linear Speed and Lower-Body Power with Changeof-Direction Speed in National Collegiate Athletic Association Divisions I and II Women Soccer Athletes. Sports (Basel), 2018; 6(2) https://doi.org/10.3390/sports6020030

Los Arcos A, Yanci J, Mendiguchia J, Salinero JJ, Brughelli M, Castagna C. Short-term training effects of vertically and horizontally oriented exercises on neuromuscular performance in professional soccer 
players. Int J Sports Physiol Perform, 2014; 9(3): 480-488. https://doi.org/10.1123/ijspp.2013-0063

Loturco I, Jeffreys I, Abad CCC, Kobal R, Zanetti V, Pereira LA, Nimphius S. Change-of-direction, speed and jump performance in soccer players: a comparison across different age-categories. J Sport Sci, 2019; 1-7. https://doi.org/10.1080/02640414.2019.1574276 [Epub ahead of print]

Loturco I, Jeffreys I, Kobal R, Abad CCC, Ramirez-Campillo R, Zanetti V, Pereira LA, Nakamura FY. Acceleration and Speed Performance of Brazilian Elite Soccer Players of Different Age-Categories. J Hum Kinet, 2018; 64: 205-218. doi: 10.1515/hukin-2017-0195

Mendez-Villanueva A, Buchheit M, Simpson B, Peltola E, Bourdon P. Does on-field sprinting performance in young soccer players depend on how fast they can run or how fast they do run? J Strength Cond Res, 2011; 25(9): 2634-2638. https://doi.org/10.1519/JSC.0b013e318201c281

Mujika I, Santisteban J, Impellizzeri FM, Castagna C. Fitness determinants of success in men's and women's football. J Sport Sci, 2009; 27(2): 107-114. https://doi.org/10.1080/02640410802428071

Pauole K, Madole K, Lacourse M. Reliability and validity of the T-test as a measure of agility, leg power and leg speed in college aged men and women. J Strength Cond Res, 2000; 14(4): 443-450

Pojskic H, Åslin E, Krolo A, Jukic I, Uljevic O, Spasic M, Sekulic D. Importance of Reactive Agility and Change of Direction Speed in Differentiating Performance Levels in Junior Soccer Players: Reliability and Validity of Newly Developed Soccer-Specific Tests. Front Physiol, 2018; 9: 506. https://doi.org/10.3389/fphys.2018.00506

Reilly T. Football. En Physiology of Sports. London: E \& FN Spon, 371-425; 1990

Reilly T, Williams AM, Nevill A, Franks A. A multidisciplinary approach to talent identification in soccer. J Sport Sci, 2000; 18(9): 695-702. https://doi.org/10.1080/02640410050120078

Sassi RH, Dardouri W, Yahmed MH, Gmada N, Mahfoudhi ME, Gharbi Z. Relative and absolute reliability of a modified agility T-test and its relationship with vertical jump and straight sprint. J Strength Cond Res, 2009; 23(6): 1644-1651. https://doi.org/10.1519/JSC.0b013e3181b425d2

Semenick D. The T-test. NSCA, 1990; 12: 36-37

Sheppard JM, Young WB. Agility literature review: classifications, training and testing. J Sport Sci, 2006; 24(9): 919-932. https://doi.org/10.1080/02640410500457109

Sheppard JM, Young WB, Doyle TLA, Sheppard TA, Newton RU. An evaluation of a new test of reactive agility and its relationship to sprint speed and change of direction speed. J Sci Med Sport, 2006; 9(4): 342-349. https://doi.org/10.1016/j.jsams.2006.05.019

Silva JR, Magalhães JF, Ascensão AA, Oliveira EM, Seabra AF, Rebelo AN. Individual match playing time during the season affects fitness-related parameters of male professional soccer players. J Strength Cond Res, 2011; 25(10): 2729-2739. https://doi.org/10.1519/JSC.0b013e31820da078

Spencer M, Pyne D, Santisteban J, Mujika I. Fitness determinants of repeated-sprint ability in highly trained youth football players. Int J Sports Physiol Perform, 2011; 6(4): 497-508

Sporis G, Jukic I, Milanovic L, Vucetic V. Reliability and factorial validity of agility tests for soccer players. J Strength Cond Res, 2010; 24(3): 679-686. https://doi.org/10.1519/JSC.0b013e3181c4d324

Stølen T, Chamari K, Castagna C, Wisløff U. Physiology of soccer: an update. Sports Med, 2005; 35(6): 501-536

Strøyer J, Hansen L, Klausen K. Physiological profile and activity pattern of young soccer players during match play. Med Sci Sport Exercise, 2004; 36(1): 168-174. https://doi.org/10.1249/01.MSS.0000106187.05259.96

Trecroci A, Longo S, Perri E, Iaia FM, Alberti G. Field-based physical performance of elite and sub-elite middle-adolescent soccer players. Res Sports Med, 2018a; 1-12. https://doi.org/10.1080/15438627.2018.1504217

Trecroci A, Milanović Z, Frontini M, Iaia FM, Alberti G. Physical Performance Comparison between Under 15 Elite and Sub-Elite Soccer Players. J Hum Kinet, 2018b; 61: 209-216. https://doi.org/10.1515/hukin2017-0126 
Yanci J, Los Arcos A, Camara J, Castillo D, García A, Castagna C. Effects of horizontal plyometric training volume on soccer players' performance. Res Sports Med, 2016; 24(4): $308-319$. https://doi.org/10.1080/15438627.2016.1222280

Yanci J, Los Arcos A, Mendiguchia J, Brughelli M. Relationships between sprinting, agility, one- and two-leg vertical and horizontal jump in soccer players. Kinesiology, 2014; 46(2): 194-201.

Yanci J, Reina R, Los Arcos A, Camara J. Effects of different contextual interference training programs on straight sprinting and agility performance of primary school students. J Sci Med Sport, 2013; 12(3): 601607

Young WB, Willey B. Analysis of a reactive agility field test. J Sci Med Sport, 2010; 13(3): 376-378. https://doi.org/10.1016/j.jsams.2009.05.006

\section{Corresponding author:}

\section{Asier Los Arcos Larumbe, PhD.}

Department of Physical Education and Sport,

University of the Basque Country, UPV/EHU,

Vitoria-Gasteiz, Spain.

Lasarte 71, 01007 Vitoria-Gasteiz, Spain.

Tel. 0034945013519.

E-mail: asier.losarcos@ehu.eus 